\title{
Regulating networks in decline
}

\author{
Christopher Decker ${ }^{1}$
}

(C) The Author(s) 2016. This article is published with open access at Springerlink.com

\begin{abstract}
Demand for some services provided on traditional postal, electricity, gas and fixed telecommunications networks can be characterized as being in decline in some jurisdictions. Declining demand can give rise to difficult questions for regulators, in particular, the extent to which network operators can fully recover the costs of historic investments, and the efficiency and distributional effects of applying different rate structures. It can also raise fundamental questions about: the on-going rationale for regulation; the essential functions provided by network operators; and whether regulations should be applied symmetrically to traditional and alternative suppliers. Depending on the pace and scale of the decline, regulation may need to adapt. Proposals for adapting regulation are identified and critically examined in this paper, particularly in terms of the approach to setting the allowed level of revenues and the determination of rate structures.
\end{abstract}

Keywords Public utility · Networks · Declining demand · Excess capacity · Economic regulation $\cdot$ Rate structures $\cdot$ Sunk cost recovery

JEL Classification K23 $\cdot$ L5 $\cdot$ L43 $\cdot$ L51 $\cdot$ L97

Christopher Decker

christopher.decker@wolfson.oxon.org

1 Research Fellow in Law and Economics, CSLS, University of Oxford, Oxford, UK 


\section{Introduction}

For much of the industrialized world, the 20th century was a period generally characterized by ever-expanding demand for services provided by traditional network utilities. ${ }^{1}$ Throughout this period, regulation has generally been premised on a number of explicit and implicit assumptions. First, the services are essential and so access should be provided on an affordable and universal basis. Second, the prospects for competition developing for network services are limited, given natural monopoly attributes. Third, demand for network services will grow, or at least remain relatively stable, over the mid to long-term. These assumptions are increasingly being called into question in some jurisdictions, as demand for certain services which utilize the electricity, gas, postal and fixed telecommunications network infrastructure appear to be in a state of sustained and irreversible decline. Expectations are that this trend will continue, and indeed accelerate in the future, which is raising questions about how these services should be regulated.

A 'network in decline' can be characterized as one experiencing a sustained, nontemporary, reduction in demand, resulting in excess capacity on large parts of the network most of the time. ${ }^{2}$ Stated differently, access to network capacity is available on most parts of the network if needed, there is limited congestion, and generally no capacity constraints. ${ }^{3}$ There are two elements to this definition of decline. First, the demand reduction is not temporary, but has been sustained over a number of years and is expected to continue, and second, that it is not isolated to specific geographic areas or 'pockets' on the network, but rather affects a substantial proportion of the network.

Utilization of traditional postal network services can be characterized as being in decline in many parts of the world. The total mail volume of the United States Postal Service (USPS) has decreased by $27 \%$ in less than a decade from 213.1 billion units in 2006 to 155.4 billion units in 2014 (Fig. 1). ${ }^{4}$ Similar declines in the transportation of mail items can be observed in many European countries, such as the UK and France (Fig. 2), and in Australia (Fig. 3).

Demand for fixed line telecommunications subscriptions in a number of jurisdictions has also been steadily declining. This has resulted in excess capacity and the underutilization of large parts of fixed line telephony networks, particularly the localloop component. ${ }^{5}$ In the USA, the number of fixed line telephone subscriptions per

\footnotetext{
1 The terms 'traditional network utility' and 'traditional network operator' are used to refer to typically incumbent operators of energy, water, rail, fixed-line telephony and postal networks. In many jurisdictions outside of the USA, such as in Europe, South America, Australia and New Zealand, these traditional operators were typically state-owned until the 1980s and 1990s, and some still remain under state ownership or control.

2 This generalizes Briglauer and Vogelsang's (2011) definition of a declining fixed telecommunications network as one that features a 'systematic and non-temporary volume decline'.

3 A reviewer observes that given new uses of the electricity grid, a more appropriate definition of 'network services' in the future may be the amount of peak $\mathrm{kW}$ being integrated and coordinated via the grid, in addition to $\mathrm{kWh}$ being delivered through the system.

4 For more detailed discussions, see Brennan and Crew (2016).

5 See Jahn and Prüfer (2008). Briglauer and Vogelsang (2011) conclude that, given the 'remarkable average volume decline' in fixed line telephony in many jurisdictions, underutilization has to be a suspected feature
} 


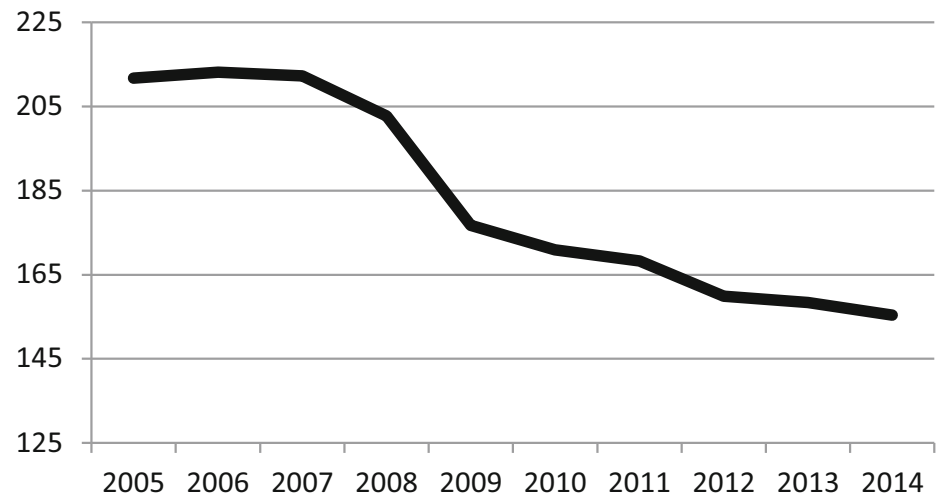

Fig. 1 United States Postal Service: total mail volume (Billions). Source United States Postal Service 'Postal Facts - A Decade of Facts and Figures'

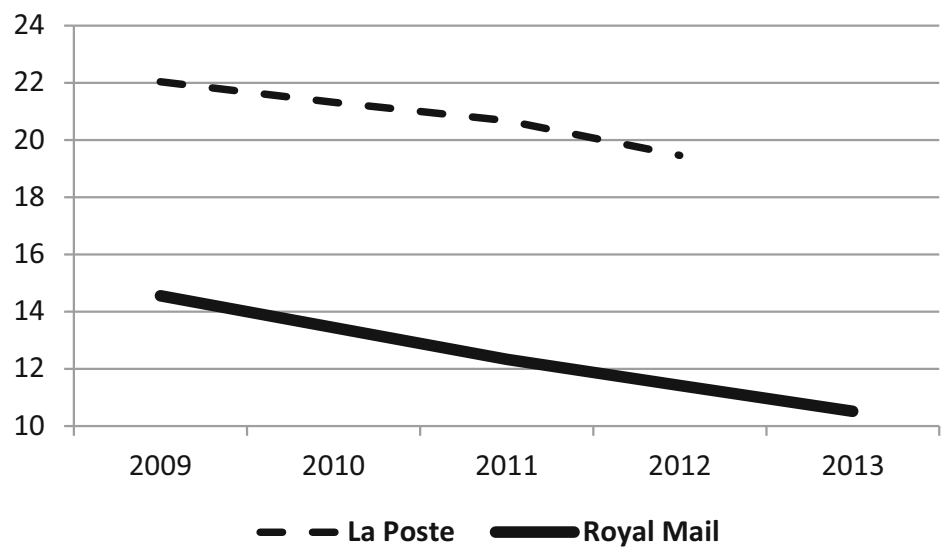

Fig. 2 Total mail items delivered in France and UK (billions). Source Post NL 'European Postal Markets: 2015 An Overview'

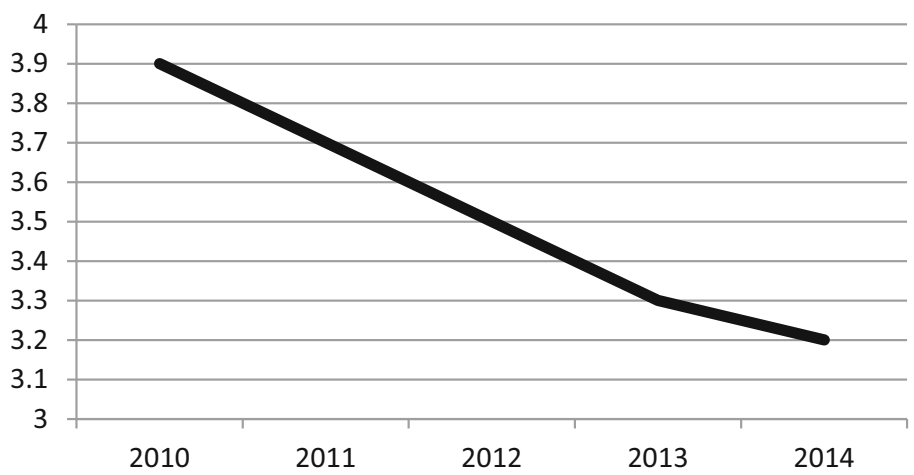

Fig. 3 Australia Post-Domestic reserved letter service (millions). Source Australia Post Annual Report 2014 


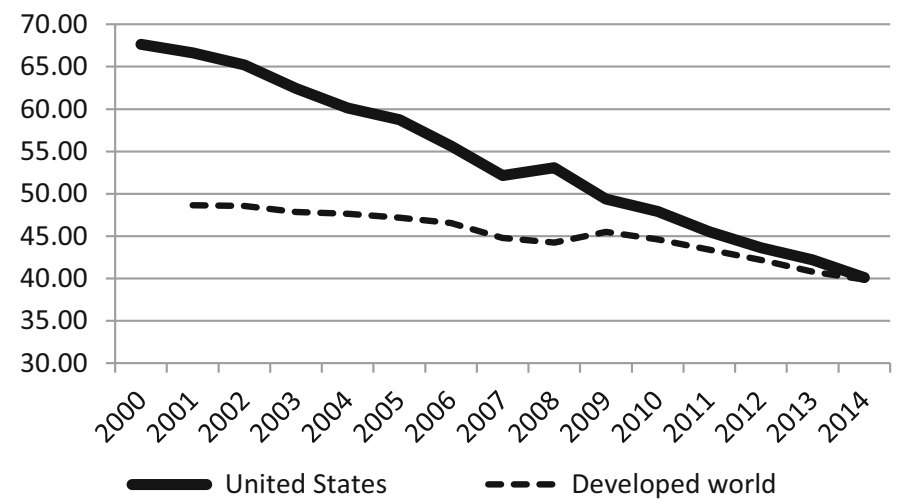

Fig. 4 Fixed-telephone subscriptions per 100 inhabitants, 2000-2014. Source ITU, statistics 2015

100 inhabitants has reduced sharply from 67.64 in 2000 to 42.22 in 2013 (Fig. 4). Recent analysis found that the number of fixed voice connections fell in 15 of 18 countries surveyed in the period between 2008 and 2013 (Ofcom 2014). ${ }^{6}$

Conventional natural gas production is decreasing in some parts of the world, and this is having an impact on demand for gas transmission services. In the UK and the Netherlands there has been a steady reduction in conventional gas production over the past 15 years, with production in the UK in 2014 less than a third of production in the year 2000 (Fig. 5). Gas demand in Europe has decreased since 2008, and most projections forecast a continuous decline in demand until 2025 (Agency for the Cooperation of Energy Regulators 2015). Forecasts also suggest declining, or flat, demand for gas volumes delivered to US residential customers in aggregate over the long-term (US Energy Information Administration 2015). ${ }^{7}$

Finally, there are projections for a decreasing rate of growth in demand for electricity consumption in some jurisdictions. In the USA there has been a steady decline in electricity demand growth over the last two decades (Fig. 6) and expectations are that, in the period to 2040, demand growth will be at around, or just below, $1 \%$. Similar projections for declining demand growth exist in Australia, and under some assumptions, for the UK (Wood and Carter 2013; National Grid Company 2013).

Notwithstanding the fact that it has long been recognized that sustained decreases in long-run demand can be a cause of great concern in the network utility industries (MacAvoy et al. 1989), there is only a small, but evolving, literature which considers the implications of network services being in decline. Briglauer and Vogelsang (2011) and Jahn and Prüfer (2008) focus on the implications of potential network overcapac-

\footnotetext{
Footnote 5 continued

of large parts of networks, particularly for the local-loop component (which is not used to transmit mobile services).

6 The exceptions being the UK, South Korea and Brazil.

7 This is the result of population shifts to warmer areas, improvements in appliance efficiency, and increased use of electricity for home heating. However, others argue, that local gas utilities are growing if metrics other than throughput are used (such as customer numbers, growth in burner tips or appliances). See American Gas Association (2015).
} 


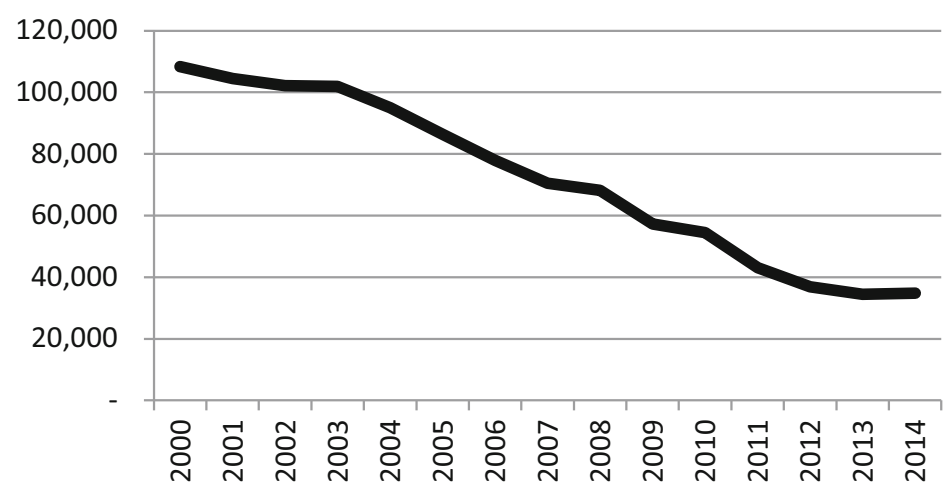

Fig. 5 UK total gas net production (million cubic meters). Source Department of Energy and Climate Change, F.2 Gas Production

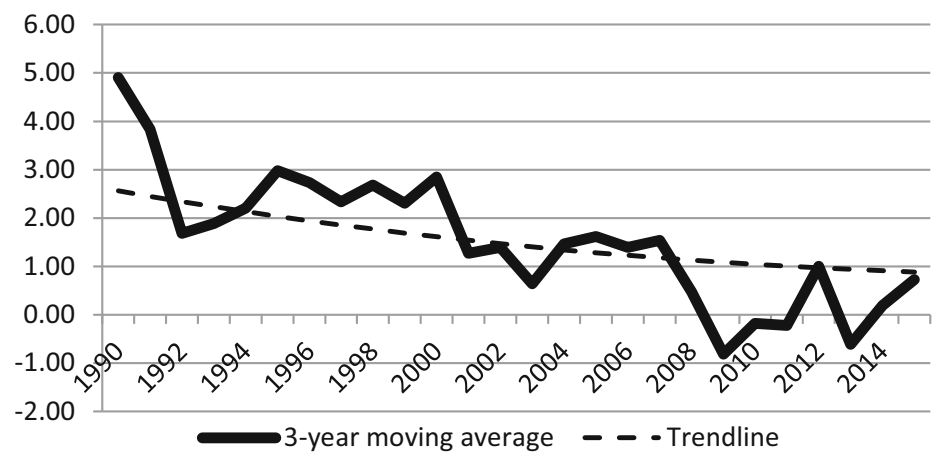

Fig. 6 U.S. electricity demand growth, 1990-2015 (percent, 3-year moving average). Source Adapted from US Energy Information Administration (2013), U.S. Electricity Demand Growth, Figure 75

ity in fixed telecommunications networks. Bourreau et al. (2012), Inderst and Peitz (2014) and Briglauer (2015) examine the related issue of how access regulation affects the incentives of incumbent and entrant firms to invest in alternative new generation networks. Faruqui $(2013,2014)$ and Hanser and Horn (2014) examine the impacts of declining demand for traditional electricity networks, while Sioshansi (2014) focuses on the wider implications of the growth of distributed generation for the electricity industry. Brennan and Crew (2016), focusing on the US postal industry, consider the effect of price cap regulation when applied to industries facing declining demand. The more general implications of the significant declines in demand for traditional mail volumes are examined extensively in Crew and Kleindorfer (2012, 2013) and Crew and Brennan (2016). ${ }^{8}$ A growing number of regulatory agencies are now engaging with the potential implications of some network services being in decline, particularly in the postal and electricity industries.

\footnotetext{
8 Although railroads are not considered in this paper, Gómez-Ibáñez and de Rus (2006) examine how different countries have adapted policy and regulation in light of the sharp decline in passenger and freight railway traffic at the end of the 20 th century.
} 
This paper examines three general issues associated with this decline for regulators and policy makers. The first issue concerns the continued rationale for regulation of those network services facing declining demand. The second issue, if regulation remains appropriate, is how regulators balance short-term and long-term efficiency considerations in these new circumstances. The third issue concerns the distribution of the impacts of declining network services, in particular, how the costs associated with services being in decline are shared between network operators and network users, and as between different types of user (captive and non-captive).

The paper is organized into 7 sections. Section 2 sets out some general factors that appear to be associated with declining demand for traditional network services in some parts of the world. Section 3 sets out some general arguments for and against any adaptation of regulation to deal with declining demand for network services. Sections 4 and 5 deal, in turn, with two of the most contentious issues associated with declining demand: whether allowed revenues should permit the full recovery of the costs of past investments in a network, and the efficiency and distributional effects of applying different rate structures. Section 6 examines three specific regulatory policy issues associated with declining network services, and Section 7 presents conclusions.

\section{Why are some network services in decline?}

The decline in demand for some services that utilize traditional utility networks can be seen across different regions and industries. This raises a question as to the factors contributing to this trend.

Across all industries, an important common driver of change in network use relates to technological change and accompanying innovation. Advances in information technology, including the digitization of information flows, has led to the development of new products and services and massive changes in how most utility networks are operated and managed. The emergence of digital products and services, including electronic mail, as well as other digital forms of communication such as SMS, online chat systems, social media and commercial information distribution apps (such as online banking apps) have had a major impact on the postal and telecommunications sectors. However, rapid technological change has also changed the way in which other networks - such as transport and energy networks-are used, operated and managed. ${ }^{9}$ Technological developments have also led to significant cost reductions for some equipment (such as mobile phones and solar PV panels), which has had the effect of changing network use, and reducing demand for traditional network services.

Changes in network use are also the result of public policy. Among the most important policies that have impacted on network use are subsidies to effect a wider change in a sector, which can have secondary effects on a network. The clearest example is the various subsidies and other favorable policy measures (such as interest-free loans or guaranteed feed-in-tariffs) used in many countries to encourage the development

\footnotetext{
9 For example, the introduction of smart meters and other technologies, such as hot water load control systems, provide scope for consumers to better manage their consumption levels.
} 
of renewable electricity facilities, including small-scale on-site distributed generation facilities. However, favorable policies and subsidies also feature in other utility industries, such as those designed to encourage the development of a digital economy, or policies directed at conservation or efficiency in the energy and water sectors.

Market-opening policies introduced in the utility industries during the 1980s and 1990s are also associated with the decline of some traditional networks. Although the scope of such policies has varied across industries and jurisdictions, they have generally been directed at opening up activities in the supply chain where there is some prospect for competition to develop. ${ }^{10}$ Common activities where competition was introduced include 'upstream' activities (such as gas exploration and production, electricity generation and mail sorting activities) and 'downstream' activities (like retailing). 'Unbundling' and the vertical separation of activities has also changed the underlying financing model for some integrated utilities, who are no longer able to cross-subsidize unprofitable activities with revenues derived from other profitable activities.

In some industries, alternative operators have emerged who compete head-to-head with traditional integrated suppliers for end consumers. ${ }^{11}$ The decline in demand for fixed line telephone subscriptions in some jurisdictions reflects substitution to mobile telephone network services. In the USA and UK an increasing number of households are choosing to use mobile networks for all of their telephony and other telecommunications needs. ${ }^{12}$ Fixed wireless networks - which do not utilize the (sub) local-loop component of the fixed telecommunications network-are also being used as a substitute for the fixed wireline network in some jurisdictions. ${ }^{13}$ The decline in fixed line subscriptions is also related to competition from cable networks, particularly in the USA, while there is also some evidence of a sharper reduction in demand for fixed line services in those countries where a 'naked DSL' product is available. ${ }^{14}$ Nevertheless, Briglauer and Vogelsang (2011) argue for caution in equating declining demand for certain telecommunications network services with excess network capacity. Substantial fixed-to-mobile substitution for national calls will not necessarily translate to excess capacity on fixed core networks. Such capacity may be re-utilized by mobile carriers to connect base stations, or by increased broadband data traffic. Similarly, while naked DSL products may reduce demand for traditional voice traffic over the fixed network, increases in data traffic from higher broadband usage may counter this tendency, increasing network utilization.

\footnotetext{
10 For more detailed discussions, see Decker (2014).

11 In some cases, alternative operators have invested in, and developed their own, network infrastructure. In other cases, alternative operators have made some investments at some points in the supply chain, but utilize some services of the traditional network operator.

12 A recent survey found that $44 \%$ of homes in the USA had only wireless telephones in 2014 (Centers for Disease Control and Prevention 2014). See also Ofcom (2010) for the UK.

13 In Australia, fixed-wireless connections are being installed as part of the National Broadband Network. For an overview see NBN (2015).

14 A consumer can purchase broadband services without also acquiring a voice subscription and can utilize so-called 'over-the-top' services, such as VoIP services. See the discussion in Ofcom (2010).
} 
Depleting natural resources is another factor contributing to the changed use of some networks. This supply side factor, which is specific to certain industries and regions, can be seen most clearly in the case of depleting conventional gas reserves in some parts of the world. ${ }^{15}$

Finally, changes in consumer preferences and behavior are contributing to changes in the use of some networks. This is most evident in the area of communications, where there is an increasingly strong preference — particularly by younger users - to communicate using different modes other than wireline (fixed) phone calls or traditional mail letters. 'New' methods of communication, which often utilize alternative networks, include: instant messaging, SMS, or web-based communication methods such as Facebook or Instagram. In the electricity industry, changing preferences of some consumers in relation to the environment and affordability is changing the way in which electricity is produced, transported and consumed. ${ }^{16}$ Important drivers of reduced demand for electricity distribution network services in some countries, including the USA, Australia and parts of Europe, are conservation and the rapid adoption of on-site distributed generation facilities. ${ }^{17}$ Further reductions in demand for grid distribution services are anticipated as storage capabilities become more cost-effective and ubiquitous. ${ }^{18}$ More generally, across a number of industries, a small, but increasing, number of consumers are looking to develop localized communication and energy supply methods, or in more colloquial terms to 'go off-grid' or 'build their own' networks. ${ }^{19}$

In sum, a number of technological, economic, consumer and policy factors appear to be driving the declining demand for services provided on traditional utility networks. In some cases (such as postal services) the factors leading to the decline can be observed across many countries, while in other cases (such as gas), the factors are more jurisdiction and industry-specific.

\section{Adapting regulation to declining networks}

\subsection{Is declining demand for network services necessarily a cause for concern?}

A number of arguments can be put forward to support the view that declining demand for network services is not, of itself, a cause for concern and that accordingly regulators should not necessarily adjust their policies. Firstly, the changes in the use of

\footnotetext{
15 However, in some parts of the world, notably the USA, this decline in conventional gas reserves is being countered by significant discoveries of non-conventional gas reserves, such as shale gas.

16 Faruqui $(2013,2014)$ attributes the changes in the USA to three principal factors: changes in consumer psychology; the effects of energy efficiency programs; and government initiatives to enhance codes and standards. He also refers to some evidence of fuel switching as a result of shale oil and gas production increases.

17 Favorable tax and subsidy policies have undoubtedly fuelled this growth and further growth is therefore dependent on policy.

18 For example, see the launch of the Tesla Powerwall on 1 May 2015 (The Times Newspaper 2015).

19 In telecommunications this involves combining various unbundled elements, while in electricity this can involve the installation of on-site generation, with in the future, the widespread adoption of storage facilities.
} 
many of the networks discussed in Sect. 2 have been associated with considerable benefits for consumers, including the development of innovative services, which offer greater speed, functionality and quality, often at lower cost. The fact that consumers are benefiting from the emergence of alternative operators, and supply methods, (and the corresponding decline in demand for traditional network services), implies that regulators should take a cautious view before changing policies or introducing new regulatory measures. Secondly, in some industries, the new, alternative network that offers substitute services (for example a mobile telecommunications network) is built, and operated, by the traditional network operator. In these circumstances, the consequent decline in demand for network services on the traditional, legacy network may have featured in the commercial decision to make the new investment. ${ }^{20}$ Third, although utilization of some services supplied by traditional network utilities are in decline, in some cases, this is being compensated by an increase in utilization of other services provided on the networks, or by the emergence of new opportunities for the network utilities. For example, while digital communications services may have reduced demand for the collection and delivery of traditional mail letters, the growth in electronic commerce-particularly distance selling-has increased the volume of parcels and packages that are being collected and delivered using postal services in many jurisdictions. Similarly, while the number of fixed voice telephone subscriptions may be in decline, the growth in broadband connections and in managed VoIP services has the potential to utilize some or all of the spare network capacity. Nevertheless such service substitution may only be partial or peripheral, and, in relation to certain services, may be neither a feasible, nor efficient, solution to declining demand for traditional network services. In such circumstances, reconsideration of the regulatory approach may be warranted.

\subsection{Reasons why regulation might need to adapt to declining demand for network services}

The decline in demand for certain network services may call into question the continuing rationale for the economic regulation of these network services. If traditional network operators no longer occupy a position of (significant) market power, aspects of economic regulation premised on such power may be unnecessary. For example, competition from alternative cable and mobile network operators may be sufficient to constrain the conduct of a fixed line telecommunications network operator, making economic regulation of certain services redundant. ${ }^{21}$ Alternative postal providers

\footnotetext{
20 Although in some cases the existential threat from a new, competing technology may be so great that the traditional network operator feels compelled to invest notwithstanding potentially adverse demand implications for its traditional network services.

21 Briglauer and Vogelsang (2011) found that, at the time, fixed-to-mobile substitution was unlikely to be sufficient to justify full deregulation. Similarly, the Australian regulator (Australian Competition and Consumer Commission 2015) recently concluded that voice services should continue to be regulated on the basis that VoIP services are not a strong substitute for traditional PSTN-based voice services, and that for a significant proportion of retail end-users, mobile voice services are not substitute for fixed-voice services. In contrast, Briglauer et al. (2011) conclude that in Austria, the competitive pressure from mobiles was sufficient to allow for the deregulation of retail market for national calls.
} 
and forms of communication, including digital communications, may be sufficient to constrain the behavior of the traditional postal network operator. ${ }^{22}$ In electricity, if storage facilities are widely adopted, and a growing proportion of consumers generate much of their electricity needs on-site, this may lead to a situation where grid-supplied network operators will no longer have a monopoly on supply, raising questions about regulation based around this premise.

Assuming that economic regulation of these network services is still considered necessary, then the regulatory framework may need to adapt to take account of the following factors. Firstly, regulation may need to adapt in recognition of the fact that although some network operators can substitute new services for traditional regulated network services, such substitutions and opportunities are not always comprehensive, and not all of the underutilized capacity on networks can automatically be re-used for another purpose. For example, the size and configuration of the delivery network required to deliver parcels is said to be different to that which is required to deliver traditional mail. ${ }^{23}$ Similarly, the local loop component of fixed line telecommunications network may be underutilized if large numbers of consumers use mobile, fixed-wireless or cable networks to make voice calls. This is particularly important where the fixed line network operator does not own or operate these alternative networks.

Secondly, regulation may need to adapt to declining networks because of cost recovery considerations. Different approaches to the recovery of any sunk costs associated with historic investments in network assets is considered in Sect. 4, while Sect. 5 considers the impacts of different rate structures on cost recovery and efficiency.

Third, regulation may need to adapt because, in some circumstances, the network operator may reduce service quality in order to cut costs. Brennan and Crew (2016) argue that, under the price-cap regulation applied to the US postal service, the possibility of improving efficiency in the context of declining demand is limited because of scale economies. They argue that, under this form of regulation, reducing service standards is management's principal option, and consequently mail delivery times have slowed, and overnight deliveries have been almost eliminated.

A fourth reason why declining networks may require changes to regulation is distributional in nature. Declining networks can create both winners and losers, and how these losses and gains are distributed among market participants may be a cause of policy concern. Most obviously, alternative network operators, who provide competing services - such as entrants into telecommunications (mobile networks) and postal markets-gain to the extent to which they are able to displace business from traditional network operators. However, a range of other parties potentially benefit from the changes such as: non-captive customers; new service providers (e.g.: unmanaged VoIP operators, like Skype, or social media providers); equipment suppliers (e.g.: PV solar panel or electricity storage manufacturers) and providers of alternative financing services (such as providers of third-party leasing or financing arrangements). The two

\footnotetext{
22 Ofcom (2012) removed traditional price controls for most of Royal Mail's services, in part, for these reasons. However, see Brennan and Crew (2014) who draw a distinction between gross and marginal substitutes in post in the context of market definition.

23 Brennan and Crew (2016) find that the 'gaping hole' in the US postal service from letter mail decline was not filled by increased parcel volume. Similar findings have been made in Australia.
} 
main parties who stand to lose from the decline in traditional networks are the shareholders and owners of the declining networks (assuming that they have not invested in the alternative networks), and the captive customers of those networks who may face higher charges because of a reduced customer base. Questions about who should bear the costs associated with declining networks, and how these costs should be allocated across captive and non-captive users, are considered in Sects. 4 and 5.

\section{Declining networks and cost recovery}

\subsection{Determining the level of allowed revenues}

A highly contentious issue associated with declining networks is whether an operator should be able to recover all its costs, particularly historic investment costs, given declining network demand. Determining the level of allowed revenues in the face of declining demand can give rise to a tension between allocative efficiency and longer term dynamic efficiency. On the one hand, if the level of allowed revenues is not adjusted to reflect new levels of demand, this can give rise to static efficiency losses as captive users are required to pay for any historic investments in network assets which are redundant given current and (expected) future levels of network utilization. Moreover, not adjusting revenues and prices to account for changes in demand can contribute to the further decline in demand for network services. This issue is sometimes discussed in terms of a so-called 'death spiral': where a fixed level of costs need to be recovered from an ever decreasing demand base, which leads to higher prices, and even lower demand. ${ }^{24}$ On the other hand, adjusting the level of allowed revenues to reflect the lower level of expected demand, and associated network size and configuration, creates stranded assets for the network operator and may create dynamic disincentives for investment. Network operators in regulated industries may be reluctant to make investments in contexts where there is some uncertainty about future levels of demand.

Whether the allowed level of revenue should be adapted in the face of declining demand depends on the specifics of the regulatory arrangements. Two general issues arise: (I) the implications of determining allowed revenues on the basis of historic or forward-looking costs; and (II) the suitability of different forms of price control, specifically rate of return approaches as compared to price caps.

A first issue is the possible implications of declining demand in circumstances where the level of allowed revenues is determined on the basis of forward looking cost estimates as compared to historic (backward looking) costs. If prices, and associated allowed revenues, are based on historic cost estimates, as occurs in some applications

\footnotetext{
${ }^{24}$ Borenstein and Bushnell (2015) discuss the 'death spiral' in electricity. Brennan and Crew (2016) identify the cost and price elasticity conditions which contribute to a death spiral. In perhaps the first discussion of such a relationship, Hotelling (1938) posited the argument that the need for some proportion of (fixed) overhead costs to be funded by prices contributed to rising railroad freight charges during the great depression.
} 
of the rate of return approach, ${ }^{25}$ then this will ordinarily be expected to include both operating costs and a fair return on any past investments as reflected in the rate base. In contrast, if a forward-looking approach is adopted, as is common in settings that apply price-cap regulation, then whether or not allowed revenues include a return on all past network investments depends on the specific approach applied. If allowed revenues are determined on the basis of a re-optimized network (as sometimes occurs in the telecommunications industry), then it will be likely that the regulatory asset value (RAV) will be reduced to reflect the lower demand, and revenues adjusted downwards accordingly. In these circumstances, the firm may not recover all of its past investments in the network, meaning that some investments are stranded. ${ }^{26}$ However, if allowed revenues provide for a return on an agreed or 'locked-in' RAV, which represents all historic investments made in the network, then prices and allowed revenues should allow for the return of all efficiently incurred costs associated with network investments (typically in the form of a return on and of capital).

A second issue concerns the effects of applying a rate of return or price cap form of regulation when demand is declining. Brennan and Crew (2016) argue that price cap regulation is unsuitable for industries with declining or sluggish growth in demand. This is because, given scale economies, an operator faces an 'uphill battle' to improve efficiency in circumstances where demand is declining. ${ }^{27}$ In contrast, under the rate of return approach, the network operator could request a rate hearing to take account of the impact of declining demand on costs.

\subsection{Possible ways of reconciling short-term and long-term efficiency considerations}

Various mechanisms have been proposed to achieve a balance between the short-run and long-term efficiency considerations of declining demand for network services. One approach is to introduce decoupling policies that detach the authorized, or allowed, revenues that the network operator can earn from the underlying demand for a service. ${ }^{28}$ Decoupling is seen to address the tension between conservation policies and the incentives of utilities to increase output. For this reason such policies are favored by

\footnotetext{
25 A reviewer points out that, in the United States, 20 states use a historic test year. The remaining states use a fully-forecasted or partially-forecasted test year.

26 Rogerson (2011) shows that if the correct cost allocation rule is applied both the historic cost and forward-looking approach can result in the firm breaking even and efficient prices irrespective of the degree of technological progress. This analysis assumes that the firm makes ongoing investments in the network, an assumption that is unlikely in a context of declining demand.

27 Two effects of declining demand are identified by Brennan and Crew (2016). The impact that decreases in output have on average costs (measured by the average cost elasticity) and the impact that decreases in demand have on price (measured by the price elasticity of demand).

28 In a nutshell, under a decoupling policy, the regulator fixes the authorized revenues that can be earned by the network utility in advance. If the utility's actual revenues are higher than this amount, because of a larger volume of sales than expected, the utility is required to pay a credit to customers. Conversely, if actual revenues are below those fixed by the regulator, the utility is able to charge a surcharge to customers for the difference. Decoupling policies effectively eliminate the regulatory lag in repricing when demand falls, rather than waiting until after a rate hearing. For more detailed discussion see Brennan (2010).
} 
conservation advocates who wish to see a reduction in demand, while at the same time encouraging network utilities not to oppose policies to reduce demand by keeping them whole. Decoupling policies are widely used in the gas, water and electricity industries in the USA in the context of energy efficiency and water conservation policies.

The main advantage of such policies is that they stabilize revenues for operators in the context of decreasing demand. However, in doing so, this approach effectively shifts the revenue risk associated with declining demand onto consumers, and as a result is likely to give rise to allocative inefficiencies. The approach also runs against the grain of price-cap type incentive regulation, which consciously eschews embodying any form of revenue guarantee. ${ }^{29}$ Moreover, while decoupling might ensure that a network operator can recover some of its costs where demand is moderately decreasing (such as a result of efficiency or conservation policies), the long-term viability of this approach is not clear in settings where demand is expected to decrease permanently and rapidly. In part, this is because one effect of decoupling policies is to increase the volumetric (or usage) charges and not fixed charges. However, as discussed below, one effect of increasing the volumetric (or usage) element is that it exacerbates the rate structure problem, and further reduces the demand for network services.

An alternative way of reconciling short-term and long-term efficiency considerations might be to introduce some form of sharing mechanism between network users and network operators, whereby the burden of paying for historic investments in network assets is shared. For example, in circumstances of irreversible declining demand, a network operator and users may agree that the rate base or the RAV is subject to a one-off revaluation. ${ }^{30}$ Some assets will be written off or marked down on the basis that they are no longer necessary to meet levels of demand. An advantage of this approach is that it minimizes the harm to allocative efficiency, while at the same time preserving dynamic incentives (provided the circumstances in which such a write down can occur are well-recognized and agreed by all parties). In limiting the potential exposure of users and regulated firms to significant losses, the logic of this approach is similar to that which supported the use of revenue or earnings sharing mechanisms as a transitional mechanism between rate of return and price cap regulation (Sappington and Weisman 2010). However, in the case of declining networks, the mechanism would be used to share the losses associated with demand being lower than expected when investments in the network were made.

\footnotetext{
29 Brennan (2013) notes that decoupling challenges the central findings of regulatory economics that fixing profits or revenues will result in various distortions and inefficiencies, and that, to incentivize efficiency, prices should be divorced from costs for a certain period of time. He concludes that the economics of decoupling strongly suggest that it is motivated by political incentives rather than economic arguments.

30 Although not related to declining demand, examples of such revaluations include the 2005 decision by the UK telecommunications regulator (Ofcom) to re-value the pre-1997 assets of British Telecom (BT) on an indexed Historic Cost Accounting (HCA) basis. This was to address concerns that BT had overrecovered more than it costs for the copper network as a result of a shift from historic costs to current (replacement) costs in 1997. In 2013, the European Commission also recommended that non-replicable telecommunications assets (such as ducts, trenches and poles) be placed in a regulatory asset base (RAB) where the initial value was determined by the value of the assets as recorded in the regulatory accounts (net of the accumulated depreciation at the time of calculation and indexed by an appropriate price index). This was, in part, to address the risk of cost over-recovery for these assets. See Ofcom (2005) and European Commission (2013).
} 
The sharing approach does however imply that the network operator will still have some stranded costs and does not fully recover all of the historic investment costs. In some jurisdictions this could be viewed as a breach of the regulatory compact and for this reason the network operator would need to agree to such a write-down. ${ }^{31}$ Vogelsang (2014) considers two options for addressing this stranded asset risk. One option is to compensate network operators above the cost of capital before stranding occurs on an ex ante basis. Although this approach cannot do much where the network is already in a state of rapid decline, and indeed might further facilitate any decline, ${ }^{32}$ it is potentially a longer-term mechanism for dealing with declining demand in industries where network operators make investments in long term assets and there is some potential for demand to fall in the future. This is because such a policy might encourage desirable investments by effectively 'front-loading' higher returns at the beginning of the life of the assets. However, this policy might be in tension with regulatory policies focused on keeping prices low. Another option is to compensate the network operator for any stranded costs ex post. However, this too will likely lead to higher prices, which may further exacerbate the decline in network demand.

\section{Rate structures}

\subsection{Allocating costs across different types of user}

Rate structures in many regulated utility industries are based around a two-part tariff structure where the access (or capacity) element of the tariff is intended to recover the fixed costs of the network (which do not vary with output), and the usage (or commodity) element of the tariff is intended to recover marginal costs (which do vary with output). As with the level of revenues discussed above, decisions as to rate structures can have important efficiency and distributive effects, particularly where demand is declining and there is a group of captive users (such as residential customers) who obtain all of their supply from a single network operator and have limited, or no, substitution possibilities.

If all users of a network (both captive and non-captive) face a common access (capacity) charge designed to recover the fixed network costs (including the costs of past investments) and a usage (commodity) charge to recover variable costs, then non-captive and captive users both contribute to the fixed costs of the network. From the perspective of captive users this may be seen as equitable, as all users of the network contribute equally to the fixed cost recovery. However, non-captive users, who obtain only a proportion of their demand from the network operator, may find this outcome inequitable on the basis that, relative to their usage, they are contributing disproportionately towards the fixed costs of a network that they may only occasionally

\footnotetext{
31 A related area has examined the consequences of asset stranding in the context of policy changes directed at opening markets and introducing competition in the utility industries. See, in particular, Sidak and Spulber (1998) for telecommunications and Brennan and Boyd (1997) in relation to electricity.

32 For example, where increases in the cost of capital lead to higher prices and further reduces demand.
} 
use. Over time this may prompt more non-captive users to abandon the traditional network altogether (and further exacerbate the reduction in demand). ${ }^{33}$

Conversely, if the rate structure is such that some proportion of fixed network costs are recovered through usage (commodity) charges, then captive customers might argue that they are contributing a disproportionate amount to the fixed costs of the network, which has been designed to service non-captive customer demand at peak periods. Applying a rate structure that involves some proportion of fixed costs being recovered through usage (commodity) charges can also change the incentives of network operators. It may, for example, encourage network operators to degrade the quality of supply to, or even refuse to service, non-captive customers who are small users on the basis that they do not fully contribute to fixed costs recovery.

\subsection{General proposals relating to rate structures in the context of declining demand}

The issue of rate structures manifests in various ways across the industries examined in this paper and, as described in Sects. 5.3-5.6 below, different approaches are applied across the utility industries. Before considering these approaches, some generic proposals for adapting rate structures in the context of declining demand are presented.

In circumstances where the substitution possibilities of different network users varies (some users are captive and others are not captive) and where substitution is not complete (most users maintain a connection to both the traditional and alternative network), one generic possibility is for network operators to introduce a 'menu' of optional two-part tariffs, with different levels of access (capacity) charges and usage (commodity) charges. ${ }^{34}$ As shown in Fig. 7, low usage non-captive customers who use the network as a back-up service could be offered a tariff with a low access (capacity) charge but a relatively higher per unit usage (commodity) charge. Another tariff, which should appeal to high usage captive customers, might offer a higher access (capacity) charge but relatively lower per unit usage (commodity) charge. Users who consume less than $\mathrm{Q}^{*}$ would prefer to choose a low access charge $\left(\mathrm{A}^{1}\right)$ and high usage charge $\left(\mathrm{p}^{1}\right)$, while users who consume more than $\mathrm{Q}^{*}$ would prefer to choose the tariff involving a higher access charge $\left(\mathrm{A}^{2}\right)$ and lower usage charge $\left(\mathrm{p}^{2}\right)$.

While this approach could, in principle, provide an efficient mechanism to recover a fixed level of costs, to be effective in practice, the network operator will need relatively precise information about different customer valuations for the service, so as to design a menu of two-part tariffs to induce captive and non-captive network users to 'self-

\footnotetext{
33 A reviewer points out that this raises similar issues to those that occur with the application of Ramsey pricing where 'captive' (inelastic demand) customers of a service can pay more than 'non-captive' (elastic demand) customers. However it has been argued that the approach can be justified because if the non-captive customers are required to pay more they will stop using the service and this will create a greater cost burden on the captive customers. This issue arose in rate hearings in the US railroad and postal sectors in the 1970s and early 1980s where the highest rates were assigned to 'captive' (inelastic demand) users. For a discussion see: Baumol and Willig (1981) and the critique of this argument by Tye (1983).

34 That is, a non-uniform two-part tariff structure; where different network users pay differential access (capacity) charges and face a variable schedule of marginal usage (commodity) prices. Generally on this approach, see Willig (1978) and Brown and Sibley (1986).
} 


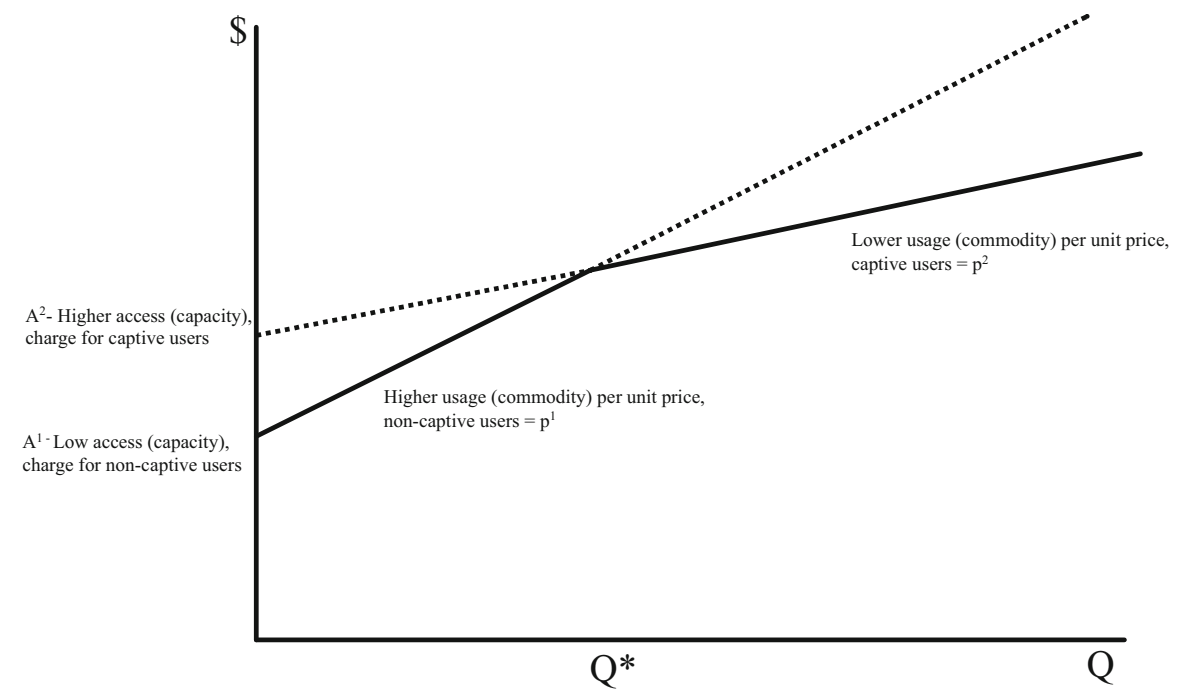

Fig. 7 Two-part tariffs to attract captive and non-captive users

select' the tariff consistent with their preferences. This task has proven difficult in practice.

Another generic possibility might be to allow the network operator to negotiate different access/usage (capacity/commodity) splits with specific types of users. This will allow the network operator to take account of the specific characteristics of the user (i.e.: whether they are high or low use, and how reliant on the network they are) and can stimulate participation in the market. However, there may be practical difficulties in applying such an approach in regulatory systems where network operators are not permitted to discriminate among users, and where the network operator directly supplies a large number of end consumers (such as in telecommunications or postal services).

\subsection{Rate structures in the electricity industry}

In the electricity industry a question currently being examined in some jurisdictions is whether current rate structures for residential and small business customers, that can involve the recovery of significant revenues from usage (commodity) charges, need to change in the context of declining growth in demand. Faruqui (2013) observes that while such a rate structure might allow for sufficient revenues to be generated in times of growing demand, when demand is declining, this can create issues for cost recovery.

A related question is whether on-site distributed generation operators-such as those with solar PV facilities-sufficiently contribute to fixed network costs under the current charging arrangements applied in some jurisdictions. ${ }^{35}$ Some US studies conclude that on-site generation operators, such as solar power installations in states

35 See NC Clean Energy Technology Center and Meister Consultants Group (2015). 
that apply net metering, do not contribute a sufficient share of revenues to cover utility costs, meaning they are cross-subsidized by other utility ratepayers (Louisiana Public Service Commission 2015; California Public Utility Commission 2013). ${ }^{36}$ The issue is, however, contentious, and other studies have concluded that so-called customergenerators produce net benefits to all customers. ${ }^{37}$

An issue likely to become prominent in the future when low-cost storage options become more commercially viable is the effect of rate structures where some proportion of fixed costs are recovered through usage (commodity) charges. If customer-generators with storage only maintain a connection to the grid as back-up, then a default supplier in an area is faced with a situation of being required to maintain a connection to a large number of customers who consume very little grid-supplied electricity, and, as a consequence, contribute to only a proportion of fixed network cost recovery. This may be exacerbated by the fact that non-default suppliers may refuse to offer contracts to small users of grid-supplied electricity on the basis that they are not profitable. 38

Various proposals have been made to adjust rate structures in the context of declining demand growth in the electricity industry. Faruqui $(2015 a, b)$ argues that a three-part tariff should be adopted to more accurately reflect the underlying cost structure. The first part of the tariff is a fixed (capacity) charge to cover metering and customer care; the second part is a demand charge (based on the maximum $\mathrm{KW}$ demand over a specified period) intended to recover the costs of being connected to the grid; and the third part should be a volumetric time-varying usage (commodity) charge. Faruqui (2015b) concludes that introducing a third-part to the tariff (i.e.: the demand charge) should reduce the volumetric (commodity) charge, but potentially increase the fixed charge. ${ }^{39}$ An alternative approach, proposed in some US states, involves increasing the access charges levied on retail distributed generation only (i.e.: a solar-PV rate) in order to recover a more significant share of fixed costs from customer-generators. ${ }^{40}$ However, such charges have proved contentious, and some studies (US Department of Energy SunShot Initiative 2014b) have argued that while they can improve the short-term cost recovery for network utilities they can be unduly discriminatory, misrepresent the potential benefits of customer-generation facilities, and do not take account of

\footnotetext{
36 Borenstein and Bushnell (2015) conclude that the political momentum to support renewable distributed generation (particularly solar, but also other intermittent sources of generation) is costly from a societal point of view, and that to the extent to which it results in a revenue shortfall for the utility, shifts costs onto the utility's remaining rate payers.

37 See references to studies in NC Clean Energy Technology Center and Meister Consultants Group (2015). See also US Department of Energy SunShot Initiative (2014b).

38 Consequently a default suppliers' customer base may come to comprise: (a) customers who consume very little from the grid as they are customer-generators; (b) are high default risk and therefore are not being serviced by other suppliers; or (c) are there by default, which means that the default supplier has to seek them out to receive payment (i.e.: new tenants in a flat who have not registered with a supplier).

39 Faruqui (2013) observes that changes in rate structures can raise difficult issues for both regulators and consumers, because as a consequence of this shift the fixed charge for many consumers may have to increase, and small consumers in particular may see their bills increase as a result of this change.

40 According to NC Clean Energy Technology Center and Meister Consultants Group (2015) in the first quarter of 2015 there were 24 proposed fixed charge increases pending or decided across different states. Of the 8 that were decided, the average increase was $41 \%$ above the existing level of fixed charge.
} 
all of the factors contributing to lower revenue recovery by utilities. A recent US Department of Energy study (US Department of Energy SunShot Initiative 2014a) advocates for an alternative approach based around revenue decoupling; a minimum monthly contribution/minimum bill for all customers; and rates that reflect the varying cost of electricity at different times of use.

\subsection{Rate structures in the gas industry}

Potentially adverse distributional and efficiency effects associated with the rate structures applied in the British gas industry-where rates are based around a variable (i.e.: non-fixed) split of the access-usage (capacity-commodity) components ${ }^{41}$ - have been subject to regulatory review. Among the distributional concerns prompting the review were that the existing rate structure might be resulting in one group of users contributing more to the recovery of fixed network costs than other users, and in addition, that certain users (shippers) might be contributing to fixed costs through two mechanisms. ${ }^{42}$ Excess capacity associated with declining network demand also raised concerns around allocative efficiency, on the basis that the fixed capacity charge was, in aggregate, potentially being set at a level below the long-run marginal cost of capacity, and the variable commodity charge was being set at levels in excess of the marginal costs of network usage. ${ }^{43}$ In response to these concerns, the British regulator (Ofgem 2014) has proposed to introduce 'fully floating' access (capacity) charges for long-term capacity products which involves the historical costs of the network being shared between all users who book capacity. Changes to the charging arrangements for short-term capacity products are also being made, including reducing short-term capacity discounts. In Europe, the recommended policy position is that the usage (commodity) component of the rate structure should only reflect short-run marginal costs, so as to avoid distortions in the behavior of shippers in the commodity markets. $^{44}$

\footnotetext{
${ }^{41}$ Specifically the commodity component of the network user tariff is periodically adjusted to account for any under-recovery of revenues from the capacity component (which are derived from entry capacity auctions) and allows the network operator an opportunity to earn its allowed revenue.

42 Shippers who acquired firm capacity rights a day ahead, or on the day, paid a discounted rate or no capacity charge. In contrast, shippers who acquired access (capacity) rights through long-term auctions in the past, and paid a non-discounted price, also faced a higher usage (commodity) charge which reflects a contribution to fixed costs.

43 Additionally, there were concerns that relative differences in the capacity/commodity split in rate structures between Britain and neighboring gas markets (such as Belgium and the Netherlands) may have led to distortions in cross-border flows of gas, insofar as cross-border trading is not being driven by differences in the cost of gas.

44 See EU THINK (2012). In order to better integrate the European gas market, at entry and exit points of interconnection between Member States, there is now a requirement that the majority of fixed charges be recovered through a capacity charge, and any commodity charges used to recover certain variable and operational costs. See Agency for the Cooperation of Energy Regulators (2013).
} 


\subsection{Telecommunications charging arrangements}

In the telecommunications industry, the continuing use of the standard pricing approach-based on forward-looking estimates of long-run average incremental cost (FL-LRAIC) - has also been called into question in the context of non-temporary decreasing demand for some fixed line services. Vogelsang (2014) argues that the rationale for FL-LRAIC pricing, which is based on prices that would encourage a competitor to put in place an alternative infrastructure, 'breaks down' in the face of declining demand. Moreover, because such an approach is based on average costs and economies of scale (decreasing long run average costs), reductions in demand will lead to increases in access prices, which will have a spiraling feedback effect and result in allocative inefficiencies. Briglauer and Vogelsang (2011) conclude that, in the context of changing demand, the pricing approach should combine the standard FL-LRAIC method with the retail-minus method. This, it is argued, will give the network operator the flexibility to lower prices below FL-LRAIC in times of contracting demand, while limiting its ability to engage in a price squeeze of competitors. Vogelsang (2014) argues that depending on whether the network is expanding or declining, optimal prices would lie in a range between a ceiling of FL-LRAIC (which would allow a contribution to fixed costs) and a floor of short-run incremental cost (where there is no contribution to fixed costs). In addition to this changed pricing approach, Briglauer and Vogelsang (2011) also consider the option of replacing per-minute charging with capacity-based charging. ${ }^{45}$

\subsection{Postal services charging arrangements}

The design of charging arrangements for the postal industry given declining demand has been examined in both analytical work and policy documents. Analytical work has principally focused on the potential for introducing different forms of non-linear pricing in the postal sector. One area of focus has been on whether the ability to charge volume discounts can assist in the financial viability of the operator in the face of inter-modal substitution, including to digital forms of communication (Crew and Kleindorfer 2012). As for other traditional networks, demand reductions in the postal sector can potentially give rise to a situation of increasing average unit costs and higher prices, which has a negative feedback effect on demand. Brennan and Crew (2016) advocate that, in the face of declining demand, changes need to be made to the price cap formula to take account of the elasticity of average cost with respect to output and the elasticity of demand. This, they argue, will allow the operator to remain solvent and retain the incentives for internal efficiency. Some regulators, such as the UK postal regulator (Ofcom 2012), have gone further and have decided to remove traditional price controls for a number of postal services to give the operator greater

\footnotetext{
45 Briglauer and Vogelsang (2011) note that this shift is likely to be particularly relevant for all IP-based networks where time is no longer a relevant measure of utilization of the network.
} 
pricing flexibility, including giving it the choice as to the most appropriate way to raise revenues to finance its universal service obligations. ${ }^{46}$

\section{Wider regulatory policy issues}

In addition to the issues associated with setting allowed revenues, and determining rate structures, three wider policy issues may confront regulators dealing with declining demand.

\subsection{Scope and funding of any 'essential functions'}

Historically, many traditional network operators have performed a number of 'essential' functions over and above simply providing network access. In telecommunications, for example, it is common for fixed line network operators to provide access to certain emergency services. Similarly, in EU member states, designated electricity distribution network operators are required to automatically offer a connection to any customer that wants to receive grid-supplied electricity. Traditional postal network operators have generally been under certain obligations with respect to the collection and delivery of mail. However, as alternative networks and supply methods develop, and a growing number of consumers switch to alternative providers, this raises a number of questions about the nature, scope and funding of these essential functions. The first issue, given the changes occurring in such industries, is whether all of the historic essential functions will continue to be necessary? (For example, if most consumers have access to digital forms of communication, is a daily mail delivery really an essential function?). Secondly, if some of these functions are still considered to be essential in the new environment, should such obligations be placed on all operators and suppliers, both traditional network operators and alternative network operators? (For example, should all communications network operators and service providers, including VoIP providers, be required to offer access to emergency services? Should all electricity suppliers, including municipal and community operators, be required to offer a connection to any customer who wishes to connect?). Thirdly, how should any essential functions be funded? This connects with debates in some industries about the future viability of 'universal service obligations' in contexts where the size of the customer base is declining. While this issue is most prominent in the postal industry, the question of how to finance a universal right of access to grid-supplied electricity is increasingly being debated in that industry. ${ }^{47}$

\footnotetext{
46 Specifically, in granting Royal Mail this flexibility, Ofcom (2012) noted: "In this uncertain time, when the position of post in relation to electronic substitutes is unclear, Royal Mail is in a better position to determine the impact of price rises of different products on overall demand and, hence, revenues." However, in 2015, Ofcom launched an interim review of these arrangements noting concerns about: Royal Mail's pricing behavior since 2012; the exit of a major end-to-end competitor; and the stronger financial position of Royal Mail. See Ofcom (2015).

47 This may be particularly important where the traditional network supplier is required to connect all customers who want a connection, but the composition of the customer base increasingly comprises those
} 
Assuming that some of these essential functions remain necessary, various proposals have been made to address the issues identified above. One proposal is that the concept of an 'essential function' is adapted. This can be seen in the changes to the universal service commitments of postal service operators in some countries, such as New Zealand and Canada. ${ }^{48}$ Another proposal is to apply essential function obligations to all operators, including both traditional and new operators. ${ }^{49}$ This approach can be seen in the area of communications, where the obligations to provide access to emergency services have, in some jurisdictions, been extended to alternative network operators. ${ }^{50}$ If all participants are not required to perform essential functions, then consideration should be given to alternative methods for financing these essential functions. Among the possibilities are: the imposition of an essential functions tax or levy on all network operators or service providers $;{ }^{51}$ the periodic appointment of a default supplier to perform these essential functions, which can charge a premium for doing so ${ }^{52}$ or funding via a direct public subsidy.

\subsection{An asymmetric regulatory approach}

The decline in demand for traditional network services is generally accompanied by an increase in demand for services provided by another, often less-regulated, network operator (Vogelsang 2014). For this reason, an observation frequently made by traditional network operators is that the decline in demand for their services is, in part, being facilitated by the application of an asymmetric regulatory approach. ${ }^{53}$ Some traditional network operators argue that, because of this asymmetric approach, they are being unduly restricted in responding to competition, and that the regulatory framework needs to adapt to ensure that there is a level playing field among traditional and alternative operators. ${ }^{54}$

Footnote 47 continued

who use limited electricity (because they have access to on-site generation or storage) or who other alternative suppliers do not wish to serve (such as customers who default on payments).

48 In New Zealand, the scope of the USO has been reduced to three deliveries a week for the majority of delivery points while maintaining five days a week to certain rural delivery points and PO Boxes. In Canada, Canada Post introduced community mailboxes to serve individual neighborhoods (although this policy proved controversial and has been halted).

49 A recent UK House of Commons inquiry in the postal industry has raised the possibility that the regulator (Ofcom) place General Universal Service conditions on other postal operators (House of Commons 2015).

50 However, there is currently debate in a number of jurisdictions about whether such obligations should also be applied to certain VoIP operators.

51 The proceeds of which are then put into a fund which is used to finance these essential functions.

52 This might be achieved through a franchise-bidding model where different operators compete to be the service provider.

53 Specifically, that the regulation of alternative network operators is less onerous and stringent with respect to service and performance obligations (e.g: quality, coverage or frequency of service) and consumer protection obligations (e.g.: requirements to connect, and employ certain billing practices and disconnection processes, and be part of dispute resolution mechanisms).

54 A more general discussion of asymmetric regulation is presented in Decker (2014). 
Determining the appropriate scope of regulation can give rise to tensions between different policy objectives. In particular, there can be a tension between policy measures to encourage greater competition, and policies directed at consumer protection and universal access. In the postal industry, for example, the claim has been made in some jurisdictions that inadequate consumer protections are placed on alternative operators to ensure consumers are protected in the event of failure at critical times (House of Commons 2015). Concerns have also been voiced in the electricity industry about the performance of, and consumer protection obligations that are placed on, non-traditional suppliers such as municipal or community grid network operators. However, the application of 'one-size-fits-all' performance obligations, or consumer protection policies, on alternative operators, irrespective of the scale or business strategy, may be disproportionate and stifle entry and innovation.

A need to ensure that regulation is proportionate and does not stifle competition and innovation, while at the same time ensuring that all operators compete on a level playing field, is currently a focus of regulators across a number of industries. In telecommunications, there is increasing appreciation of the need to develop policy in this area in response to the growing use of services such as VoIP. The EU Digital Agenda is currently looking at ensuring a 'level playing field' for new and traditional market players (European Commission 2015). In the USA, there are concerns that, absent a federal policy on the regulatory treatment of services such as VoIP, a patchwork of state-by-state regulations will emerge. This is a response to moves by some state Public Utility Commissions (PUC) to designate VoIP as a 'telecommunication service' and to subject providers to the consumer protection, universal service, and carrier of last resort obligations that apply to traditional telecommunications providers. ${ }^{55}$

In the electricity industry, the regulatory treatment of non-traditional electricity suppliers is currently being reviewed in the USA, UK and Australia (Ofgem 2015; Australian Energy Regulator 2014; Arizona Corporation Commission 2014). Among the questions being examined are whether such non-traditional suppliers should be regulated in a similar way to traditional suppliers (on the basis that they supply electricity), and if not, what specific economic regulation, consumer protection and performance obligations they should face.

\subsection{Implications of declining demand for network capacity allocation methods}

Various methods for allocating network capacity are applied across the industries discussed in this paper, including: administrative methods (such as where capacity allocation occurs on a first-come-first-served basis, or some form of 'grandfathering' of rights occurs); bilateral negotiations between a network operator and a user; and auction-type allocation mechanisms, including open season-type arrangements.

\footnotetext{
55 These attempts have proven controversial and it is reported that legislatures in over half of the US states have passed legislation that prohibits the state PUCs from regulating VoIP services. For example, in California the state legislature prohibited the PUC from regulating VoIP services until 2020. It is claimed that this legislation is intended to stop PUCs retarding innovation by imposing regulatory costs on Internet services.
} 
A relevant question is which of these capacity allocation methods is likely to be most appropriate in the context of declining demand for network capacity.

Generally speaking, capacity auctions can be an efficient mechanism for the allocation of capacity in situations where capacity is constrained and there are a sufficient number of bidders i.e.: there is competition (McDaniel and Neuhoff 2002; McDaniel 2003). In addition, it is sometimes argued that long-term auctions can provide important market 'signals' regarding the future need for investments in network capacity (Brattle Group 2002; LECG 2011) ${ }^{56}$ This latter function is, however, controversial, and there is some skepticism about the relevance and appropriateness of using auctions to decide and fund investments for some networks (McDaniel and Neuhoff 2002; Stern and Turvey 2003; Helm 2003; Newbery 2003). ${ }^{57}$ In any event, in settings where demand is not growing, and there is no congestion on the network, the use of auctions may be disproportionately complex, and it may be more appropriate to adopt other capacity allocation methods based on estimates of marginal cost. Specifically, if there is excess capacity at all points on a network (no capacity constraints) then there is no scarcity value, and any auction price will be zero or the reserve price (Brattle Group 2002). This implies that the use of auctions as a capacity allocation mechanismsuch as currently occurs in the British gas market and in electricity markets in some jurisdictions-may need to be re-examined in the context of declining demand for network capacity. In particular, where there is limited congestion on a network, a 'first-come-first-served' approach may be preferable because of its simplicity.

Vogelsang (2001) and Hogan et al. (2010) present an alternative two-part tariff structure that could be used as a capacity allocation mechanism where demand fluctuates. Within a given price constraint, periodic adjustments to the fixed capacity and variable usage components of a two-part tariff are used to manage the tension between optimal (short-run) capacity utilization and optimal (long-term) capacity investment.

\section{Conclusions}

This paper has considered a range of regulatory issues that can arise when demand for traditional network services declines. The extent to which regulators will confront the issues identified depends, among other things, on: the pace of the decline in demand; whether the decline in demand for one set of network services is compensated by an increased demand for other services which utilize the network; whether the traditional

\footnotetext{
56 Yarrow (2003) argues that the use of auctions for establishing future gas capacity needs reveals information that is deregulatory in its intent, and that this allows for the development of the transportation system to be driven more by market processes (including the demand side) and less by monopolistic planning processes.

57 Stern and Turvey (2003) argue that that there might be a bias toward underprovision of new capacity in circumstances where any new incremental capacity expansion reduces the price that can be charged for all capacity, and therefore involve lost revenues on existing capacity. Helm (2003) argues strongly against the position that auctions could in some way replace the traditional CAPEX planning approach to determining investment. Helm notes that while the auction can provide information which tests a CAPEX plan, the determination of the CAPEX plan rests with the network operator and not the auction. Newbery (2003) expresses concern about the use of auctions to guide investment decisions in contexts where bidders are uncertain about the ability of regulators to commit to future actions.
} 
network operator also owns and operates an alternative network providing substitute services; and the nature and scope of any efficiency and distributional issues which might arise. Moreover, while declining network demand is a feature of utility industries in some parts of the world, it is by no means a universal phenomenon. Utilization of traditional networks varies according to industry and jurisdiction, which in part, reflects the different drivers of the change in network use (technological, economic, consumer and policy).

However, where it is a feature, declining demand for network services can raise challenging questions for regulators and policymakers. Important among these is the foundational question around the continuing rationale for regulation of the network service. Where continuing regulation is merited, this can give rise to a tension between setting prices that encourage the efficient utilization of the network and allowing for the recovery of past investments in the network. Regulatory decisions on these issues can involve a wider trade-off between short-term allocative efficiency and longerterm dynamic efficiency. Choices as to allowed revenue recovery and rate structures can also have important distributional impacts, implying that the effects of network services declining can be spread unevenly among captive and non-captive users. Regulatory decisions on efficiency and distributional questions will likely attract political interest. $^{58}$

While a need to balance efficiency and distributional considerations is familiar territory for regulators, given the high stakes involved, declining demand for network services can make the trade-offs stark. Traditional network operators will resist regulatory policies that might contribute to a 'death spiral'; alternative operators and suppliers will argue against regulatory policies that might discourage competition and innovation; and captive users will argue that fixed costs should be spread evenly among all network users irrespective of use. To the extent to which they arise, reconciling these different interests is likely to be a major challenge for regulators faced with declining demand for network services in the future. It may also require regulators to consider whether anticipatory policies might be adopted to encourage investments in contexts where there is a strong possibility of a future decline in demand for network services, and therefore some stranding of assets.

Acknowledgments I am grateful to the editor and four anonymous referees for helpful comments and corrections. All remaining views and errors are my own.

Open Access This article is distributed under the terms of the Creative Commons Attribution 4.0 International License (http://creativecommons.org/licenses/by/4.0/), which permits unrestricted use, distribution, and reproduction in any medium, provided you give appropriate credit to the original author(s) and the source, provide a link to the Creative Commons license, and indicate if changes were made.

\footnotetext{
58 To take one example, the Australian Department of Communications recently made a submission to the independent telecommunications regulator (ACCC) as part of its review of fixed-line telecommunications network prices, which noted that: "The ACCC's treatment of redundant assets and adjustments to cost allocation to deal with asset under-utilisation and loss of economies of scale appear to prevent Telstra recovering relevant costs....the proposed price reduction is inimical to price stability and smooth pricing transition path to the NBN (National Broadband Network)." See Australian Government Department of Communications (2015).
} 


\section{References}

Agency for the Cooperation of Energy Regulators. (2013). Framework Guidelines on rules regarding harmonised transmission tariff structures for gas. FG-2013-G-01. 29 November 2013.

Agency for the Cooperation of Energy Regulators. (January 2015). European Gas Target Model: Review and update.

American Gas Association. (September 18, 2015). Got Growth? Defining US gas utility growth in an era of efficiency and natural gas resource abundance.

Arizona Corporation Commission. (December 22 2014). In the matter of the commission's inquiry into solar distributed generation business models and practices and their impacts on public service corporations and their ratepayers.

Australia Post. (2014). Annual Report 2014.

Australian Competition and Consumer Commission. (October 2015). Public inquiry into final access determinations for fixed line services: Final decision.

Australian Energy Regulator. (November 2014). Regulating innovative energy selling business models under the National Energy Retail Law. Issues Paper.

Australian Government Department of Communications. (July 17 2015). ACCC further draft decisioninquiry into primary prices for fixed-line services.

Baumol, W., \& Willig, R. (May 1 1981). Verified statements before the ICC in Ex Parte 347, Coal Rate Guidelines-Nationwide.

Borenstein, S., \& Bushnell, J. (2015). The US Electricity Industry after 20 Years of Restructuring. NBER Working Paper 21113.

Bourreau, M., Cambini, C., \& Doğan, P. (2012). Access pricing, competition, and incentives to migrate from "old" to "new" technology. International Journal of Industrial Organization, 30, 713-723.

Brattle Group. (2002). Convergence of non-discriminatory tariff and congestion management systems in the European Gas Sector. Report for the European Commission.

Brennan, T. J. (2010). Decoupling in electric utilities. Journal of Regulatory Economics, 38, 49-69.

Brennan, T. J. (2013). Energy efficiency policy puzzles. The Energy Journal, 34, 1-25.

Brennan, T. J., \& Boyd, J. (1997). Stranded costs, takings, and the law and economics of implicit contracts. Journal of Regulatory Economics, 11, 41-54.

Brennan, T. J., \& Crew, M. (2014). Gross substitutes versus marginal substitutes: implications for market definition in the postal sector. In M. A. Crew \& T. J. Brennan (Eds.), The role of the postal and delivery sector in a digital age. Northampton: Edward Elgar.

Brennan, T. J., \& Crew, M. (2016). Price cap regulation and declining demand. In M. A. Crew \& T. J. Brennan (Eds.), The future of the postal sector in a digital world. New York: Springer.

Briglauer, W. (2015). How EU sector-specific regulations and competition affect migration from old to new communications infrastructure: recent evidence from EU27 member states. Journal of Regulatory Economics, 48, 194-217.

Briglauer, W., Schwarz, A., \& Zulehner, C. (2011). Is fixed-mobile substitution strong enough to de-regulate fixed voice telephony? Evidence from the Austrian markets. Journal of Regulatory Economics, 39, 50-67.

Briglauer, W., \& Vogelsang, I. (2011). The need for a new approach to regulating fixed networks. Telecommunications Policy, 35, 102-114.

Brown, S. J., \& Sibley, D. S. (1986). The theory of public utility pricing. Cambridge: Cambridge University Press.

California Public Utility Commission. (2013). California Net Energy Metering (NEM) draft costeffectiveness evaluation.

Centers for Disease Control and Prevention. (January-June 2014). Wireless substitution: Early release of estimates from the National Health Interview Survey. Released 12/2014.

Crew, M. A., \& Brennan, T. J. (2016). The future of the postal sector in a digital world. New York: Springer.

Crew, M. A., \& Kleindorfer, P. (2012). Non-linear pricing, volume discounts and the USO under entry. In M. A. Crew \& P. R. Kleindorfer (Eds.), Multi-modal competition and the future of mail (pp. 1-17). Northampton: Edward Elgar.

Crew, M. A., \& Kleindorfer, P. (2013). Reforming the postal sector in the face of electronic competition. Northampton: Edward Elgar.

Decker, C. (2014). Modern economic regulation: An introduction to theory and practice. Cambridge: Cambridge University Press. 
Department of Energy and Climate Change. (2015). F.2 Gas Production. Retrieved from https://www.gov. uk/government/uploads/system/...data/.../dukesf_2.xls

EU THINK. (January 2012). EU involvement in electricity and natural gas transmission grid tarification. Final Report.

European Commission. (2013). Commission Recommendation of 11.9.2013 on consistent nondiscrimination obligations and costing methodologies to promote competition and enhance the broadband investment environment'. C(2013) 5761 (final).

European Commission. (2015). A digital single market strategy for Europe. SWD, 100.

Faruqui, A. (June 2013). Surviving sub-one-percent growth. Electricity Policy, 2-11.

Faruqui, A. (2014). Strategies for surviving sub-one percent growth: An American perspective. In Presentation at ACCC/AER Regulatory Conference 2014.

Faruqui, A. (May 14, 2015a). The global movement toward cost-reflective tariffs. In EUCI Residential Demand Charges Summit. Denver, CO.

Faruqui, A. (November 8, 2015b). The movement towards deploying demand charges for residential customers. NARUC $127^{\text {th }}$ Annual Meeting.

Gómez-Ibáñez, J. A., \& de Rus, G. (2006). Competition in the railway industry: An international comparative analysis. Northampton: Edward Elgar.

Hanser, P., \& Horn, K.-V. (2014). The next evolution of the distribution utility. In F. P. Sioshansi (Ed.), Distributed generation and its implications for the utility industry (pp. 231-251). Oxford: Academic Press.

Helm, D. (2003). Auctions and energy networks. Utilities Policy, 11, 21-25.

Hogan, W. W., Rosellón, J., \& Vogelsang, I. (2010). Toward a combined merchant-regulatory mechanism for electricity transmission expansion. Journal of Regulatory Economics, 38, 113-143.

Hotelling, H. (1938). The general welfare in relation to problems of taxation and of railway and utility rates. Econometrica, 6, 242-269.

House of Commons. (2015). Competition in the postal services sector and the Universal Service Obligation. Ninth Report of Session 2014-15.

Inderst, R., \& Peitz, M. (2014). Investment under uncertainty and regulation of new access networks. Information Economics and Policy, 26, 28-41.

ITU. (2015). Fixed telephone subscriptions. Retrieved from https://www.itu.int/en/ITU-D/Statistics/ Documents/statistics/2015/Fixed_tel_2000-2014.xls

Jahn, E., \& Prüfer, E. (2008). Interconnection and competition among asymmetric networks in the Internet backbone market. Information Economics and Policy, 20, 243-256.

LECG. (March 2011). Market design for natural gas: The Target Model for the Internal Market. A report for Ofgem.

Louisiana Public Service Commission. (February 27, 2015). Estimating the impact of Net Metering on LPSC Jurisdictional Ratepayers.

MacAvoy, P., Spulber, D. E., \& Stangle, B. E. (1989). Is competitive entry free? Bypass and partial deregulation in natural gas markets. Yale Journal of Regulation, 6, 209-247.

McDaniel, T., \& Neuhoff, K. (May 2002). Use of long-term auctions for network investment. University of Cambridge DAE Working Paper No. 0213.

McDaniel, T. (2003). Auctioning access to networks: Evidence and expectations. Utilities Policy, 11, 33-38.

National Grid Company. (July 2013). UK future energy scenarios.

NBN. (2015). nbn Fixed Wireless Connections. Fact Sheet. Retrieved from http://www.nbnco.com.au/ content/dam/nbnco/documents/fixed-wireless-factsheet.pdf

NC Clean Energy Technology Center and Meister Consultants Group. (2015). The 50 States of Solar Q1 2015.

Newbery, D. M. (2003). Network capacity auctions: promise and problems. Utilities Policy, 11, 27-32.

Ofcom. (August 18 2005). Valuing copper access. Final Statement.

Ofcom. (2010). The Consumer Experience 2010. Retrieved from http://www.ofcom.org.uk/static/tce-10/ fig-5.html

Ofcom. (March 27 2012). Securing the Universal Postal Service: Decision on the new regulatory framework. Statement.

Ofcom. (2014). International Communications Market Report. Retrieved from http://stakeholders.ofcom. org.uk/binaries/research/consumer-experience/tce-14/TCE14_research_report.pdf

Ofcom. (July 17 2015). Review of regulation of Royal Mail. Discussion Paper. 
Ofgem. (December 12 2014). Gas transmission charging review: Our policy position on future charging arrangements.

Ofgem. (May 25 2015). Non-traditional business models: Supporting transformative change in the energy market. Consultation Paper.

Post NL. (2015). European Postal Markets: 2015 An Overview. Retrieved from http://www.postnl.nl/en/ Images/European-Postal-Markets-2015-An-Overview_tcm9-22110.pdf

Rogerson, W. P. (2011). On the relationship between historic cost, forward looking cost and long run marginal cost. Review of Network Economics, 10, 1-29.

Sappington, D. E. M., \& Weisman, D. L. (2010). Price cap regulation: what have we learned from 25 years of experience in the telecommunications industry? Journal of Regulatory Economics, 38, 227-257.

Sidak, J. G., \& Spulber, D. F. (1998). Deregulatory takings and the regulatory contract: the competitive transformation of network industries in the United States. Cambridge: Cambridge University Press.

Sioshansi, F. P. (2014). Distributed generation and its implications for the utility industry. Oxford: Academic Press.

Stern, J., \& Turvey, R. (2003). Auctions of capacity in network industries. Utilities Policy, 11, 1-8.

The Times Newspaper, (May 2 2015). Power to the people in the energy revolution. page 1.

Tye, W. B. (1983). The postal service: Economics made simplistic. Journal of Policy Analysis and Management, 3, 62-73.

United States Postal Service. (2015). Postal facts—a decade of facts and figures.

US Department of Energy SunShot Initiative. (August 2014b). Rethinking standby and fixed cost charges: regulatory and rate design pathways to deeper solar PV cost reductions.

US Department of Energy SunShot Initiative. (November 5 2014a). Getting a win-win: Distributed solar and utility cost recovery.

US Energy Information Administration. (2013). Annual Energy Outlook 2013 with projections to 2040.

US Energy Information Administration. (2015). Annual Energy Outlook 2015 with projections to 2040.

Vogelsang, I. (2001). Price regulation for independent transmission companies. Journal of Regulatory Economics, 20, 141-165.

Vogelsang, I. (2014). Regulating in the face of declining demand. In Presentation at ACCC/AER Regulatory Conference.

Willig, R. D. (1978). Pareto-superior nonlinear outlay schedules. Bell Journal of Economics, 9, 56-69.

Wood, T., \& Carter, L. (December 2013). Shock to the system: Dealing with falling electricity demand. Grattan Institute Report No. 2013-15.

Yarrow, G. K. (2003). Capacity auctions in the UK energy sector. Utilities Policy, 11, 9-20. 